\title{
FAMILIAL SCOLIOSIS
}

\author{
A CLINICAL REPORT
}

Gordon C. Robin and Tirza Cohen, Jerusalem, Israel

From the Scoliosis Clinic and the Department of Human Genetics, Hadassah University Hospital, Jerusalem

Scoliosis appeared in fifteen members of a family in three generations. The eight members examined showed an idiopathic type of scoliosis. Father-to-son transmission occurred more than once. Although at first appearance transmission of the scoliosis is as an autosomal dominant trait, the concept of polygenic inheritance, as has been shown in previous population studies, could also explain the inheritance in this family.

During the past five years it has become increasingly accepted that "idiopathic" scoliosis is a genetically determined disease. Although De George and Fisher (1967) suggested from twin studies that environmental factors in utero were possibly more important than genetic factors per se, the population studies and investigations of relatives of patients that have been done by WynneDavies (1968), Filho and Thompson (1971), Cowell, Hall and MacEwen (1972), and Riseborough and WynneDavies (1973) all strongly suggest that genetic factors are involved in the inheritance of scoliosis.

\section{CASE REPORTS}

Late in 1972 five children, members of a family that had recently immigrated to Israel from Canada, were referred to the scoliosis clinic because of "back trouble". On examination it was found that each of the siblings suffered from scoliosis, four of them right thoracic curves and one a left lumbar curve. Clinical examination revealed no sign of any other disease, in particular neurological disorders or neurofibromatosis, nor was there any sign of Marfan's syndrome. Radiographs showed typical idiopathic curves ranging in severity from 10 degrees in the youngest child examined, a five-year-old girl, to 55 degrees in the oldest, a boy of seventeen. Two other siblings were not seen at this time but it was reported that the first, the oldest girl aged twenty-three, also suffered from a spinal curvature while the other, the fourth in the family, a girl of fourteen, was the only child without a spinal deformity. The mother of the children volunteered that the husband suffered from scoliosis.

At a later visit, the father (III-3 in Figure 1) was seen. He had a moderately severe right thoracic curve of about 50 degrees. He reported that each of his three sisters also suffered from scoliosis, one having undergone surgical treatment in adolescence. Their father, too, was said to have a spinal deformity. At this visit the remaining two siblings were examined and the presence of a 40-degree right thoracic curve in the oldest daughter was confirmed. The fourteen-year-old daughter showed no clinical or radiological sign of scoliosis.
Several months later the paternal grandfather of the five children originally seen arrived in Israel and consented to be interviewed and examined. He was nearly seventy years old and showed a severe right thoracic curve which he claimed had worsened considerably in the past ten years. From his memory, and from those of his son and another cousin, a physician in Jerusalem, the family tree reported here was constructed (Fig. 1).

\section{TYPE OF CURVE AND TREATMENT}

Eight members of the family with scoliosis were examined by one of the authors (G. C. R.). Hospital records were available of one patient who had undergone surgical treatment in Toronto in 1937 (III-1). Medical information was also available on another member who had recently undergone spinal fusion in Montreal, and on her younger brother who was being treated in a Milwaukee brace (children of III-10).

Ten of the patients had right thoracic curves. One, a twelve-year-old girl, had a 15-degree lumbar curve, with some structural rotation in the thoracic region also. Two of the eleven had undergone spinal fusion, and operation had been advised in another patient but refused. Of the five children presented, an attempt at treatment by braces failed in one because of lack of cooperation. Operation was suggested but so far has not been accepted. Two other girls are cooperating with braces. Two others with curves of under 20 degrees are being followed for progress.

\section{FAMILY HISTORY}

Information was collected on fifty-two members of the family over five generations (Fig. 1). The great-grandfather of the presenting children married twice, and scoliosis was known in children of both marriages. Nothing is known, however, of the descendants of the second marriage beyond the first generation. Among descendants of the first marriage, scoliosis was common, and appeared in no less than fourteen members in three generations. Because thirty-one of the fifty-two family

Professor Gordon C. Robin, F.R.C.S., Department of Orthopaedic Surgery, Mayer de Rothschild Hadassah University Hospital, P.O.B. 499, Jerusalem, Israel.

Dr Tirza Cohen, Department of Human Genetics, Mayer de Rothschild Hadassah University Hospital, P.O.B. 499, Jerusalem, Israel. 


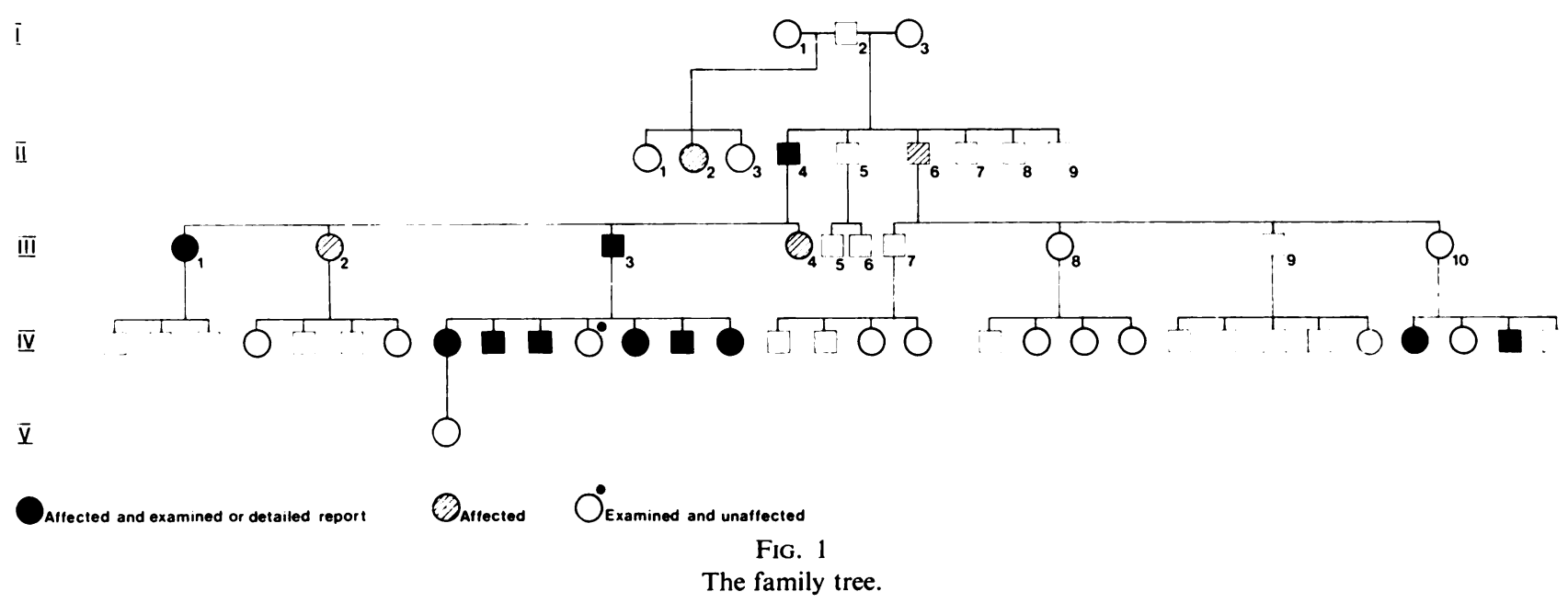

members recorded are members of the generation which is still to a large extent of school age, it is possible that even more cases of scoliosis will appear as the younger children reach adolescence. The fifth generation, so far as it is recorded, consists of one member only, a girl aged two years.

\section{DISCUSSION}

Forty years ago Garland (1934) reported a family in which scoliosis appeared over several generations. He concluded that the deformity was transmitted as a Mendelian dominant. Cowell et al. (1972) suggested that the transmission might be sex-linked because they could find no father-to-son passage in their series. WynneDavies (1968) believed, however, that a multifactorial mode of inheritance was involved. Filho and Thompson (1971) and Riseborough and Wynne-Davies (1973) repeated this claim.

From the pedigree illustrated in Figure 1 it is obvious that the scoliosis in this family originated with individual I-2. Even though it is not known whether I-2 was himself affected, the occurrence of affected offspring by both of his wives, who were unrelated, strongly suggests that he transmitted the condition. Three of his nine children were affected. In total, five affected individuals gave rise to ten affected and twelve unaffected children. Male-tomale transmission is apparent from I-2 to II-4 to III-3, and to his three sons, and also from I-2 to II-6. This rules out sex-linkage. In this kindred, therefore, scoliosis apparently behaves as an autosomal dominant trait. However, penetrance is not complete, as evidenced by individual III-10, who is normal but nevertheless transmitted the trait to her children.

The pedigree does not conflict with the polygenic mode of inheritance suggested by Wynne-Davies (1968). Edwards (1960) proposed that familial aggregations of polygenes may in some instances simulate monogenic inheritance. If such an aggregation had occurred in this family, it is not through consanguinity, since no such matings were recorded. However, the spouses have not been examined and their contribution to the disease is not known. Carter (1969) outlined criteria for polygenic inheritance with a threshold effect and Riseborough and Wynne-Davies (1973) observed many of them in idiopathic scoliosis. The disorder is common, the affected manifest a deviation from normal sex ratio, there is decreasing prevalence from first to second and second to third degree relatives, and the risk to siblings of probands with affected parent is much higher than when no parent is affected.

In summary, therefore, it seems that although the pattern of inheritance is compatible in the family reported here with an autosomal dominant trait demonstrating partial penetrance, the concept of a familial aggregation of polygenes, already suggested as the factor involved in idiopathic scoliosis, can just as readily explain the observations.

Supported by the Englander Scoliosis Research Fund.

\section{REFERENCES}

Carter, C. O. (1969) Genetics of common disorders. British Medical Bulletin, 25, 52-57.

Cowell, H. R., Hall, J. N., MacEwen, G. D. (1972) Genetic aspects of idiopathic scoliosis. Clinical Orthopaedics and Related Research, 86, 121-131.

De George, F. V., and Fisher, R. L. (1967) Idiopathic scoliosis: genetic and environmental aspects. Journal of Medical Genetics, 4, $251-257$. Edwards, J. H. (1960) The simulation of Mendelism. Acta genetica et statistica medica, 10, 63-70.

Filho, N. A., and Thompson, M. W. (1971) Genetic studies in scoliosis. Journal of Bone and Joint Surgery, 53-A, 199.

Garland, H. G. (1934) Hereditary scoliosis. British Medical Journal, 1, 328.

Riseborough, E. J., and Wynne-Davies, R. (1973) A genetic survey of idiopathic scoliosis in Bcston, Massachusetts. Journal of Bone and Joint Surgery, 55-A, 974-982.

Wynne-Davies, R. (1968) Familial (idiopathic) scoliosis. Journal of Bone and Joint Surgery, 50-B, 24-30. 